\title{
Beyond perspectives: Integrating local Indigenous knowledge/s into humanities and social science education
}

\begin{tabular}{|c|c|}
\hline Janice Crerar & Melanie Mullins \\
Charles Darwin University & Charles Darwin University \\
janicecrerar@icloud.com & \\
\hline
\end{tabular}

Keywords: Indigenous knowledge; Indigenous education; Australian curriculum

Ngan'gi culture is still one in which people are highly connected to the plants and animals of their land. This isn't a choice; we rely on plants and animals to sustain us both physically and spiritually. (Miriam-Rose Ungunmerr-Baumann, 2013, p. 5)

\begin{abstract}
The importance of including Aboriginal and Torres Strait Islander histories and cultures in mainstream education is highlighted in the current Australian Curriculum. Through inclusion as a cross curricular priority, policy makers and authors of the curriculum aim to address two needs. First, to ensure that Aboriginal and Torres Strait Islander students see their cultural identity and knowledge reflected in their school experiences; and second, that all students can engage in reconciliation, respect and recognition of the world's oldest continuous living culture (ACARA, 2014). These aims are addressed across states and territories through their branding of the curriculum, often with an emphasis on Aboriginal and Torres Strait Islander perspectives for the various learning areas (ACARA, 2014). How these curriculum aims are translated into classroom practice and educational opportunities is as diverse as Aboriginal and Torres Strait Islander cultures, histories and perspectives across Australia.

Aboriginal and Torres Strait Islander cultures and histories fall clearly within the domain of the Humanities and Social Sciences (HaSS) curriculum, which has a historic and contemporary focus to the study of human behaviour and interaction of social, cultural, environmental, economic and political context (ACARA, 2014). The focus of the following paper is on integrating Aboriginal and Torres Strait Islander histories and cultures and HaSS education as outlined in the Australian curriculum in the context of a remote community in the Northern Territory (NT) of Australia called Nauiyu.
\end{abstract}

\section{Walking and talking}

The context for writing the paper is the Growing Our Own project where the authors have worked together to learn and teach HaSS education within an Indigenous cultural context. In the process, both authors had roles as teachers and learners due to their different cultural backgrounds, experiences and perspectives. Author 1 was a lecturer and Author 2 was a pre-service teacher. Ultimately, Author 2 gained HaSS curriculum and pedagogical knowledge that enabled her to effectively design and develop successful learning experiences for Indigenous students. Author 1 gained insight into the culture and history of Nauiyu and also received guidance on integrating Aboriginal and Torres Strait Islander histories and cultures into units for pre-service teachers in a respectful and authentic way.

In keeping with this shared learning, the writing of the paper followed the authors in a journey around Nauiyu as they talked about working together on the HaSS unit. It started with a walk close to the banks of the Daly River.

It was a dry season day in Nauiyu and we were retracing our steps along the banks of the Daly River. On our last walk here, one of us had been student and the other teacher; this time we were co- authors discussing the importance of two ways learning. 
Church, previously the largest structure in the community, now overshadowed by the sports building across the oval. We looked towards the river and talked.

Author 1: We have been here before, when you were looking at different parts of the community for the history and geography assignment.

Author 2: Yes, I remember we talked about the river and the soil.

Author 1: This time we are talking about why learning about these things is important for the children here.

Author2: Yes, why they should learn both ways, traditional and western knowledge.

Figure 1: Nauiyu community

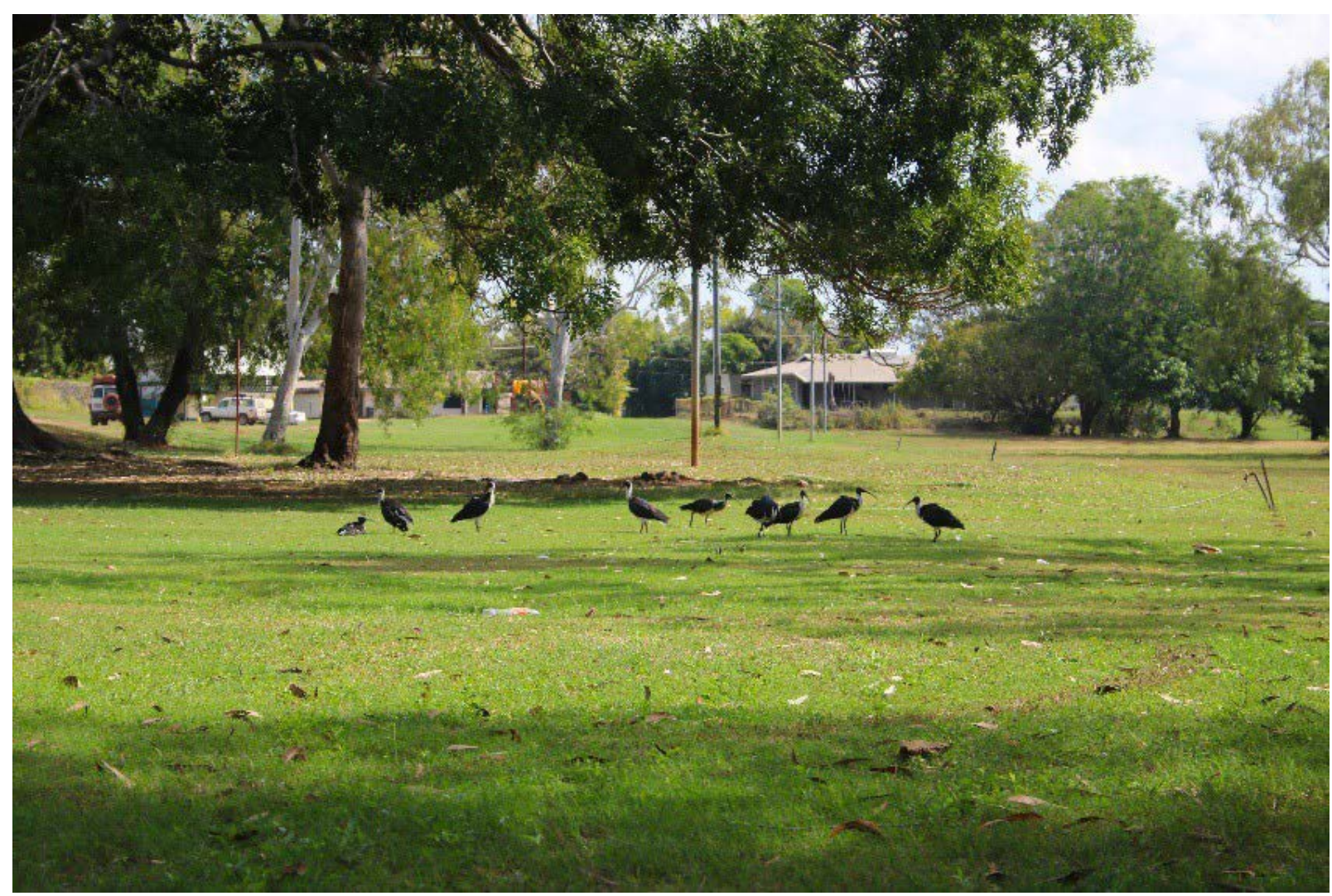

Source: Amander Dimmock, 2018.

\section{Country, language and culture}

Nauiyu is located on the banks of the Daly River, 225 kilometres south-west of Darwin in the NT. As we stand at the river, we are surrounded by the traditional country of the Malak Malak people, an area described as "wonderfully diverse" (McTaggart, Yawalminy, Wawul, Kamarrama, Ariuu, Kumunerrin, Kanintyanyu, Waya, Kannyi, Adya, Tjifisha, \& Wightman, 2014, p. 11).

The community itself is surrounded by small hills and bushland, with floodplain, kuderri billabongs and creeks close to the community. In the near distance, the ninmumggurr escarpment dominates the landscape. It is less floristically diverse on the sandstone than much of the surrounding country, with Malgin spinifex dominating, except for the rainforest pockets at the base before the land turns into open plains. 
The open country is ngityirr tyikmempi black soil planes, areas rich with eucalypts, Yerrsya cycad, Yerrgi and Yerrisynge miyerrmi types of pandanus, Merrepen sand palms, commonly used for weaving, and Wurrmuy spear grass, important for signalling that bush foods are ready to be harvested. Introduced plants and animals also prevail, some, like Miwatypala Rosella, are named from the word watypala, which means "food from white-fellas" (McTaggart et al., 2014, p. 193).

Figure 2: Merrepen sand palms

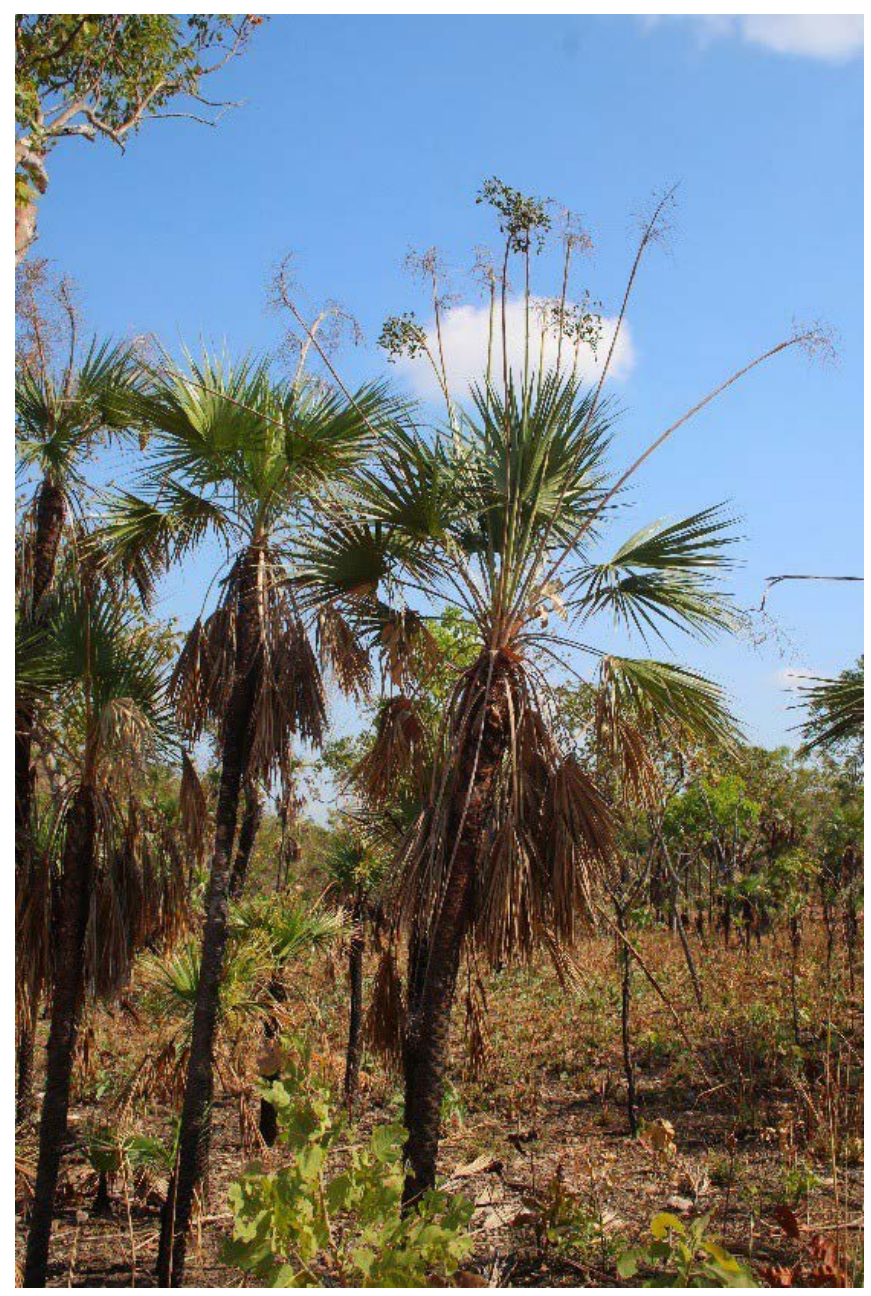

Source: Amander Dimmock, 2018.

\section{Language}

Traditionally, there are ten different language groups within the Daly River region. However, in 2018 most people spoke Kriol ${ }^{1}$ or Aboriginal English, and only a few people were speakers of Ngan'gikurunggurr and Ngan'giwumirri, two language groups that are collectively named Ngan'gi (McTaggart et al., 2014). Ngan'gi is described as a "rich language with a highly complex grammar and elaborate vocabulary" (Reid, 2018, p. 1). Data from the Second National Indigenous Languages Survey (Marmion, Obata, \& Troy, 2014) indicated that most people in the community speak either Kriol or local traditional languages at home, however, the language of formal education in the local schools is predominantly English. This is due to the "first four hours in English" approach, established in NT schools in 2008 (van Gelderen, 2017), and the fact that relatively few local Indigenous teachers have been employed in remote Indigenous schools. 
While country, language and culture are important parts of everyday life for local people in Nauiyu, there is concern about the general wellbeing of youth in the community. The high rate of youth suicide and substance abuse have been recognised problems (Miriam Rose Foundation, n.d.). Lack of success at school is considered a contributing factor to this decline and there is a need for strategies that enable children to grow strong in culture while accessing education that will enable them to compete for employment in their local community (Miriam Rose Foundation, n.d.).

The character of language and culture has been shaped considerably by ongoing colonisation processes, including the prevalence of visiting teachers who generally speak in English rather than using the local language. Overall, the history focuses on stories of settlement, farming, mining and missionaries but a few of the written reports include detail of bloody exchanges between the Malak Malak people and local miners in the late 1800s (Miriam Rose Foundation, n.d.).

\section{Settlement history}

The area was discovered by Europeans under the direction of Boyle Travers Finnis, the first governor of the proposed settlements in the NT in 1865. The river and surrounding area were named after Dominick Daly, the then governor of South Australia. The area was farmed for Puliki cattle, Miyerrkadi peanuts and sugar until the early 20 th Century and a cattle station still remains in the area today. Copper mining was established in the 1880 s and this brought violent interchanges between the miners and local people. Many of these incidents were reported in the South Australian Weekly chronicle between the years 1884 and 1886. Most of the reports concerned "natives murdering men" associated with the mine (South Australian Weekly Chronicle, 1886b). In 1886, the murder of three miners allegedly led to an indiscriminate and disproportionate massacre of local Aboriginal people (Elder, 2016) but the newspaper reported that "there is no evidence to prove that any natives were killed" (South Australian Weekly Chronicle, 1886a).

The dissonance of reported history is important for HaSS education, since local oral histories can be in discord with recorded events. A reminder that a range of perspectives are required when reviewing history and culture for education purposes and for an understanding of people's lives.

This history is important since, not long after the reported massacres, around 1886, the Jesuits set up a mission across the river from the copper mine. They wanted the local people to be away from the "evil influence that the white people had" on them (Diocese of Darwin, 2017, p. 1). At that time, the local people were living a traditional hunting and gathering lifestyle, but the missionaries worked to introduce Christianity and farming practices. The Jesuits abandoned the mission in 1899 after a large flood washed away buildings and also because of failing crops, sickness and general lack of interest from the local traditional people of the area.

Settlement from commercial ventures followed and local people started to work with Chinese and European settlers who were farming Miyerrkadi peanuts, Nugitin tobacco and other crops. By the early 1950s, many local people were living at a place called Bob's Yard and at a cement block near the Bulbul bridge. At that time, welfare authorities were sending local children away to school in Garden Point on the Tiwi Islands. This caused great sadness to the local people. As a measure to keep the children closer, the local Elders approached Bishop O' Laughlin in Darwin and asked for help to set up a health clinic and school for the people of Daly River (Diocese of Darwin, 2017). In response, the Bishop worked to establish a mission on the Daly River at a place now called Nauiyu. The school and associated dormitories were looked after by the Daughters of our Lady of the Sacred Heart and the Missionaries of the Sacred Heart.

\section{Nauiyu now}

Within this setting, with its rich traditional culture, history and lived experience of colonisation processes, the learning and teaching of history and geography is an ever-present concept. Standing on the dirrkuri river bank, we remember working together to study HaSS content knowledge and pedagogy for units within the Bachelor of Education. The place where we were standing was a study site for a Geography 
project.

The sand is red where the ants have dug nests; the other soil is black, sandy and loose on top but very compact underneath. In western knowledge, the red soil indicates the presence of iron oxides and the black colour suggests high organic matter within the soil. We had previously had a conversation about the soil, plants and the river.

Author 2: Why is the soil red do you think? [Pointing to an area where the ants have dug a nest and red soil has spilled onto the surface]

Author1: It tells us that the soil has iron oxides in it, when it is exposed to air and moisture, it appears red. In science it is because of oxidation processes. Does the colour of the soil mean anything to you?

Author 2: The colours are used for ceremony and art; the red and yellow ochre soils are important for this. Everything in nature is important to the community, it connects to our culture. We look for signs in nature to tell us different seasons. [points to trees and the river as examples] Yeninggisyi red kapok tree flowers in Ngunuwe mid-build up. This tells us that it is time to go and collect fresh water crocodile eggs. In Wurr begin derripal early dry season, the dragon flies tells you that the Barramundi are ready.

Afterwards, we both comment on the different perspectives of our knowledge, the western system focused on factors about the soil while the local knowledge moved from the soil to seasons, trees, animals and explained relations between one and other. This holistic approach is an important aspect of Indigenous knowledge (Christie, 2016), which differs from the reductionist and analytical approach of western science and geographic terms.

\section{Relationships in the environment}

As we stand close to the river, talking about different knowledge systems, we ponder on the benefits of learning from each of these different ways of knowing, for all children as well as local. From a western perspective, we recognise the rich opportunities for learning geography and history in this place. Within our sights are features of the four earth spheres, lithosphere, biosphere, hydrosphere and atmosphere; each would provide excellent examples for geography learning and teaching. We also stand next to the church, a symbol of the historic path to development of the community as it is today. This would be an excellent place to start a historic inquiry. In conversation, we explore the importance of local children understanding both ways of knowing about the world.

In Aboriginal culture, understanding the relationships between animals, plants and the environment is important because of the constant messages about bush tucker, bush medicine and the wellbeing of the environment. Understanding the balance helps local people identify when changes are occurring. Questioning these changes and observing the interactions of plants, animals and the earth helps identify and monitor problems. This is particularly important, since the impact of both global and local problems can be monitored. In the global west, where this understanding of connectivity has become the realm of professional ecologists, the art of understanding has been removed from everyday life and people are disconnected from their environment. Consequently, changes and issues can go unnoticed.

While Aboriginal knowledge is important for holistic understanding of the earth, there are also advantages to Indigenous children having a solid understanding of western knowledge systems since they are more likely to engage with employment if they can understand western perspectives. We discuss the advantages of all children understanding Indigenous knowledge to some extent.

Author 1: Do you think non-Indigenous children, even in cities around Australia, would benefit from learning about Aboriginal knowledge? 
Author 2: It is good for them to have another way to look at the environment, to learn about other cultures and different ways understanding.

Author 1: There is a strong spiritual connect in Aboriginal culture, do you think it is important for non-Aboriginal people to understand this?

Author 2: Yes, by understanding this they will know more about how changes to country through mining and other things affect Aboriginal people.

Author 1: Do you think this is something that could be part of geography education?

Author 2: Yes, it would just be part of it with learning about culture, land and places.

Author 1: Who could teach children these things, could it be their teacher?

Author 2: Yes, but only if they are Aboriginal.

In this short interchange, we recognise there will be limitations to the extent that a non-Indigenous teacher can integrate Aboriginal and Torres Strait Islander knowledge into their learning and teaching experiences. This will be discussed further on in this paper.

\section{At the river crossing}

We drive on to the river crossing, passing the new bridge to Peppimenarti and Wadeye on route. We talk about them extending the bitumen so that the road becomes easier for people to drive between the communities. There is still a long way to go before the drive from Nauiyu to Wadeye becomes easy and most of the dirt track is impassable in Wurr wirribem dudutyamu mid wet season and Wudupuntyurrutu late wet season. Flooding is common in the area and people from Nauiyu community are often evacuated at some point during the wet season.

Figure 3: Daly River Crossing

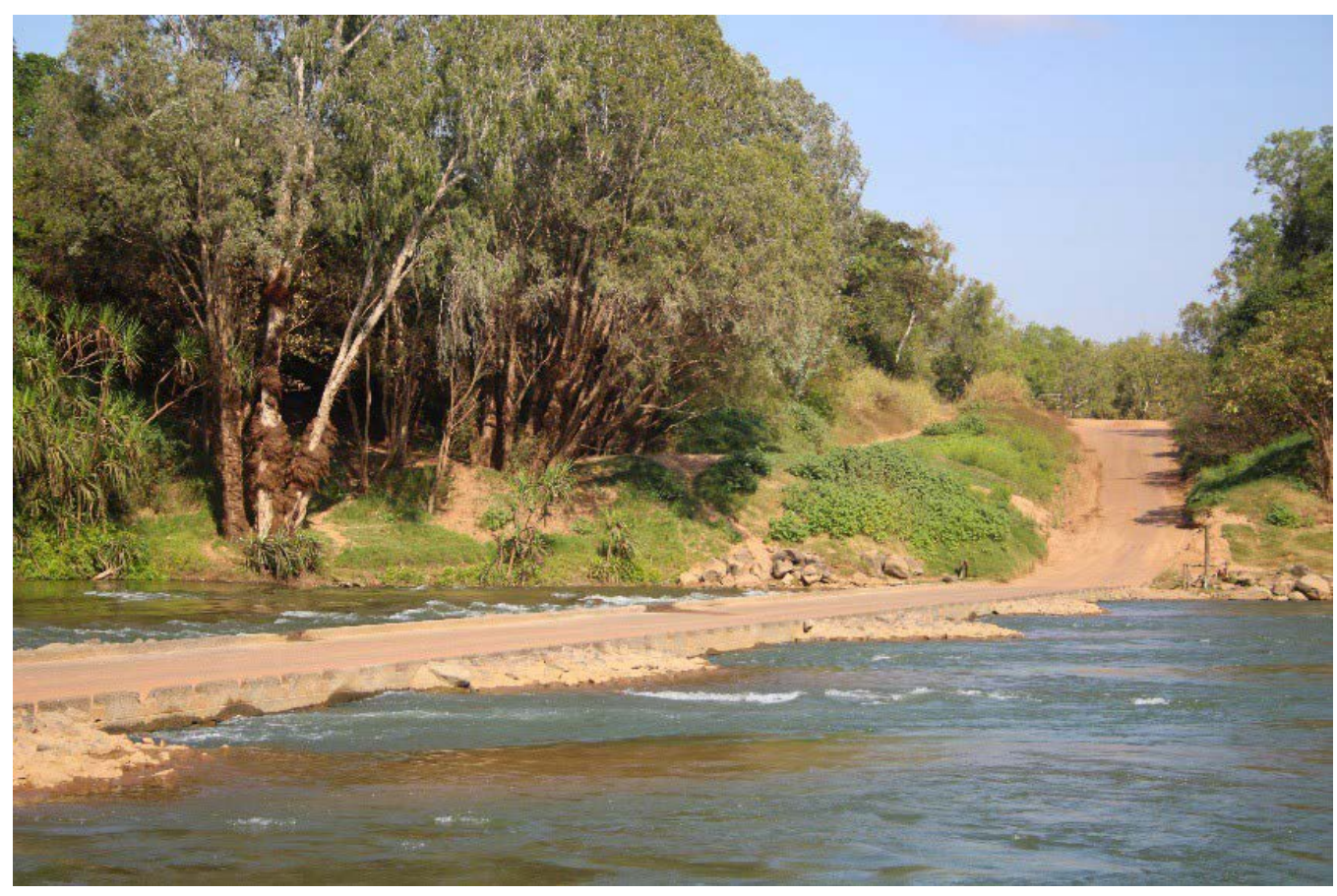

Source: Amander Dimmock, 2018. 
The river crossing is busy with visiting fishermen in their small boats weighed down where they sit at the back with the motor. It is a surprising sight, since this is a river with many awarrapun saltwater crocodiles (Crocodylus porosis). Despite this, local children commonly swim at a certain point in the crossing; a point where the river course is rocky, water is clear and awarrapun and other animals would be easily spotted. It requires understanding of the river and constant vigilance to ensure safety.

Author 1 remembers passing over the crossing in a troopie ${ }^{3}$ with GOO pre-service teachers and a few women Elders from the community at another time. The women Elders became concerned when they saw a European family swimming with two young children directly across the river from where local people were swimming. The Troopie was stopped while the women Elders called frantically in language. Their gestures were enough for the family to quickly get out of the river, particularly when the women pointed to where a crocodile lurked not far from where they were swimming.

There is much to learn for children in this community; traditional knowledge that helps them thrive and survive in their traditional culture and country of thousands of years, and then there is western knowledge, which will help them thrive and survive in the culture of the global west that is evident in 21 st Century Australia.

\section{Building a resource package}

Not far from the river crossing is Yerrmanggi Itchy Grub tree (Barringtonia Acutangula) the focus of a resource package developed by Author 2 as part of her primary education studies for a science unit.

Figure 4: Itchy Grubb tree roots and leaves
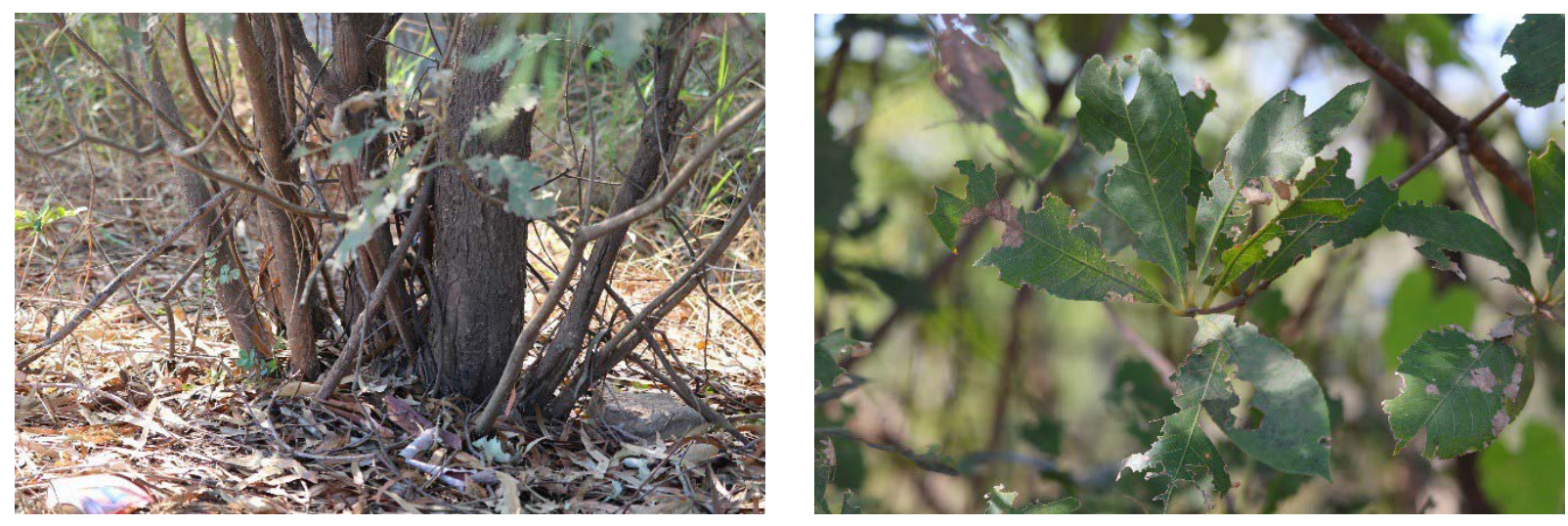

Source: Amander Dimmock, 2018.

The nature of the resource means that it provides rich holistic knowledge and information that will link to several curricula learning areas, including HaSS and the Aboriginal and Torres Strait Islander Cross Curriculum Priority (ACARA, 2014). The assignment called for development of a resource for teachers to demonstrate application of an Indigenous technological solution to an everyday problem, a task that opened a conversation about perspectives.

Author 2: It starts with a problem?

Author 1: Yes, it asks you to look for a technological solution to that problem and then create a resource.

\section{Author 2: What kind of problem?}

Author 1: Maybe like a need for food, medicine, heat, light - should we brainstorm ideas? 
Author 2: But everything does more than one thing! There is not one solution or one problem!

Author 1: Do we need to look at it differently? Should I give you time to think?

Author 2: Yes.

Author 1: Tell me when you are ready.

Author 2 sits thoughtfully looking through the book co-authored by her Grandmother Kitty Kamarrama. After sometime she calls out to let Author 1 know she is ready to discuss the assignment.

Author 2: I want to talk about the Yerrmanggi itchy grub tree, it is the solution to many things. It gives Woomera, spears, nesting for turtle food, leaves for cooking

Yerrmanggi itchy grub tree is the technological solution to many problems. Weapons are made from the branches, the roots provide nesting area for short neck turtles, which make excellent food, and the leaves provide tenderising agents for the cooking of the turtles. The fact that Indigenous knowledge systems tend to be more holistic than western knowledge is reflected in Author 2's approach to the assignment. The obvious technological solutions on the list are woomera and spears, but ultimately the focus of the assignment was on turtles, tenderising leaves and the cooking process since this was women's business rather than men's business.

\section{Integrating Aboriginal and Torres Strait Islander knowledge}

It is important to understand the relationship in Indigenous culture between knowledges and the right to knowledge. Australian teachers are required to integrate Aboriginal and Torres Strait Islander history, culture and perspectives into their learning and teaching programs, but the curriculum documents do not explore the many layers of complexity inherent in this requirement. Questions arise about whose history, culture and perspectives should be included; what knowledge the teachers have the right to discuss; and how teachers can access what they need to know in order to provide authentic and respectful learning experiences.

\section{Beyond perspectives}

The need to integrate Aboriginal and Torres Strait Islander history and culture and western knowledge systems in school education is evident in communities like Nauiyu, since it is essential for the children's physical and spiritual wellbeing (Ungunmerr-Baumann, 2013). It makes sense to integrate local culture, knowledge and practices with western education during the school day. It is well recognised, through research and practice, that children learn best when taught in their mother language (Simpson, Cafferty, \& McConvell, 2008). However, the formal language of education in all NT schools is English ${ }^{4}$, and education in remote Indigenous schools is often facilitated by non-Indigenous teachers from other parts of Australia.

St Francis Xavier Catholic School in Nauiyu is different because it employs three teachers who identify as Indigenous, two of whom qualified through the GOO program. These teachers are well placed to integrate local Indigenous history and culture in HaSS education while reducing language barriers in the school environment. They can provide leadership in Aboriginal and Torres Strait Islander history and culture education within their community. There are also benefits in this situation for non-Indigenous teachers. Firstly, non-Indigenous teachers can harness the benefits of working in a remote community setting where language and culture are strongly integrated into the school work. Secondly, they will learn

4 In 2008, the Northern Territory Government with support from the Commonwealth Government determined that the first four hours of schooling must be in English, this had significant impact on the Northern Territory bilingual education program in remote communities (Simpson, Cafferty, \& McConvell, 2008). 
the principles of integrating this cross-curricular priority respectfully and authentically and be able to provide leadership for other teachers when they return to mainstream Australian communities.

\section{A perspective from Nauiyu}

We sit in the cool of the GOO study room at St Francis Xavier school reviewing the Australian Curriculum and discussing the different perspectives and priorities.

Author 1: What do you reckon, is this an important thing for all students across Australia to learn?

Author 2: Yes, this has value for kids here on community but also important for kids in Darwin and other cities. They should know this, no matter where they come from, so they can understand why country is so important to Aboriginal people and why what they do on country affects us so much. People who live in Australia should know what it was like before they came here and what happened here, to help them respect and understand.

Author 1: What about the spiritual connection to land, do you think it would help people understand this, so that they would know the effect of things like mining and fracking on Indigenous people?

Author 2: Yes, very much. It affects us very personally, deeply. They should understand this, it is important, and they should know about sacred sites. Just as important that students here know the western knowledge though, so they can understand about western ways like mining and fracking and be able to discuss with people.

Author 1: We agree that it is important to teach both ways, western and Indigenous about country and culture but who should do this? Should it be a teacher?

Author 2: Yes, but only if they are one of us (Aboriginal or Torres Strait Islander)

Author 1: But who should teach this when there are no Indigenous teachers?

Author 2: That is a problem.

\section{Conclusion}

In this paper, we argue that considering how Indigenous people would like their history and perspectives integrated into Australian education is essential for effective teaching and learning in all educational settings.

In the context of Nauiyu, there is a history of rich cultural story-telling in the teaching of HaSS through which the country, culture and history comes to life. This is possible in this community with local teachers but the question is, who should teach this information elsewhere? This paper has posed the problem of teachers with limited resources being required to integrate Aboriginal and Torres Strait Islander histories and cultures authentically and respectfully, according to the Australian Curriculum. We also have concerns that the Australian curriculum suggests that teachers invite local Aboriginal and Torres Strait Islander people to present their history and culture to a classroom of students without payment because educational funds are scarce in many areas.

We remember where we started this discussion, when we talked about the soil and laughed at our different perspectives. We shared our knowledge systems and ideas for integrating these different perspectives in educational settings. We conclude that all teachers can learn and teach HaSS but there needs to be many more Indigenous teachers to integrate these particular cross curricular priorities effectively, respectfully and authentically. 


\section{References}

Australian Curriculum, Assessment and Reporting Authority (ACARA). (2014). Cross Curriculum Priorities: Aboriginal and Torres Strait Islander Histories and Cultures. Retrieved from: https://www.australiancurriculum.edu.au/f-10-curriculum/cross-curriculum-priorities/ aboriginal-and-torres-strait-islander-histories-and-cultures/

Christie, M. (2016). Decolonising social sciences in remote Australia. Contributions to Alternative Concepts of Knowledge, 4, 143.

Diocese of Darwin. (2017). Aboriginal communities. Retrieved from http://www.darwin.catholic.org.au/ aboriginal- communities/sub-nauiyu.htm,12 June 2018.

Dickson, G. (2016). Kriol - the largest language spoken exclusively in Australia, National Accreditation Authority for Translators and Interpreters, retrieved from https://www.naati.com.au/news-events/ news-events- container/updates/kriol-the-largest-language-spoken-exclusively-in-australia/

Elder, B. (2016). Daly River, NT: Small town for anglers and holidaymakers on the Daly River. Retrieved from http://www.aussietowns.com.au/town/daly-river-nt

Harris, S. (1990). Two-way Aboriginal schooling: Education and cultural survival. Canberra: Aboriginal Studies Press.

Marmion, D., Obata, K., \& Troy, J. (2014). Community, identity, wellbeing: the report of the Second National Indigenous Languages Survey. Canberra: Australian Institute of Aboriginal and Torres Strait Islander Studies.

Miriam Rose Foundation. (n.d.). About Nauiyu. Retrieved from: http://www.miriamrosefoundation.org.au/ about- us/about-nauiyu

McTaggart, P.M., Yawalminy, M., Wawul, M., Kamarrama, K., Ariuu, C.M., Kumunerrin, T., Kanintyanyu, M., Waya, T., Kannyi, M., Adya, H. \& Tjifisha, L., \& Wightman, G. (2014). Ngan'gikurunggurr and Ngen'giwumirri plants and animals: Aboriginal biocultural knowledge from the Moyle River area, north Australia. Darwin: Merrepen Arts, Culture and Language Aboriginal Corporation, Department of Land Resource Management Northern Territory.

Reid, N. (2018). Ngan'gi Language. Retrieved from https://ngangi.net/

Simpson, J.H., Caffetry, J., \& McConvell, P. (2008). Gaps in Australia's indigenous language policy: Dismantling bilingual education in the Northern Territory, Canberra: AIATSIS Discussion Paper Number 24.

South Australian Weekly Chronicle. (1886a). Alleged Massacre of Aborigines. Saturday 23 January. Retrieved from https://trove.nla.gov.au/newspaper/article/93849455, 12 October 2018.

South Australian Weekly Chronicle. (1886b). The Murders at the Daly River copper mine, Saturday 20 February. Retrieved from https://trove.nla.gov.au/newspaper/article/93849962,12 October 2018.

Ungunmerr-Bauman, M. R. (2013). Foreword. In McTaggart, P.M., Wightman, G., Yawalminy, M., Wawul, M., Kamarrama, K., Ariuu, C.M., Kumunerrin, T., Kanintyanyu, M., Waya, T., Kannyi, M., Adya, H. \& Tjifisha, L. (2014). Ngan'gikurunggurr and Ngen'giwumirri plants and animals: Aboriginal biocultural knowledge from the Moyle River area, north Australia. Merrepen Arts, Culture and Language Aboriginal Corporation, Department of Land Resource Management Northern Territory, Australia.

van Gelderen, B. (2017). Growing Our Own: A 'two way' place-based approach to Indigenous initial teacher education in remote Northern Territory. Australian and International Journal of Rural Education, 27(1), pp. 14-28. 